\title{
Study on the Reform in Education of Ancient Chinese Juan Wei ${ }^{1, a,{ }^{*}}$ \\ ${ }^{1}$ Nanjing Yutong Experimental School, Nanjing, China \\ aquanguoc110@163.com \\ ${ }^{*}$ Corresponding author
}

Keywords: Reform in education, Instructional objective, Teaching angle, Sinology

\begin{abstract}
Ancient Chinese is basically a compulsory course for all Chinese language and literature majors. It is also a language tool for reading ancient books and inheriting ancient cultural heritage, the basis for studying the ancient literature, history, philosophy, linguistics and culture. Furthermore, it is the basis for further exploring the origin and development of modern Chinese. The most important thing is the transmission tool of Chinese culture. At the same time, under the background of the rapid development of the times and the diversification of knowledge channels, extensive application of teaching tools and teaching equipment makes it being urgent to improve the teaching methods in ancient Chinese. It is of great significance to reform the teaching of ancient Chinese. It is not only beneficial to teachers' teaching work, but also conducive to students' better knowledge of ancient culture.
\end{abstract}

\section{浅议古代汉语教学改革}

\author{
魏娟 $1, a^{*}$ \\ 1南京宇通实验学校, 南京, 江苏, 中国 \\ aquanguoc110@163.com \\ *通讯作者
}

关键词: 教学改革; 教学目的; 教学角度; 国学

中文摘要: 古代汉语基本上是大部分汉语言文学专业的必学课程, 也是我们阅读古代文献典 籍、了解古代文化知识和继承古代文化传统的语言工具, 更是学习和研究古代文学、史学、 哲学、语言学和文化学等学科的基础, 同时还是进一步探求现代汉语起源和发展的基础, 最 重要的是中华文化方块字继续传承的传播工具。并且, 在时代发展迅猛, 学生掌握知识途径 多样化的大背景下, 教学工具和教学设备的广泛应用, 使得古代汉语旧有教学方法亟待改进。 改革古代汉语教学意义重大, 既有利于教师教学工作的进行, 也有利于学生更好的学习古代 文化知识。

\section{1. 教师改变对古代汉语的传统认识}

1.1 根据性质, 应时而变

对教师来讲, 目的太单一，不仅束缚了古代汉语教学多样化的发展，而且使教学走向了 死胡同。语言学界的前辈们很早就明确提出了古代汉语教学目的是培养学生阅读古书的能力, 现在的教学大纲也非常明确的有了相应的规定。作为一门语言工具课, 这一教学目的无疑是 正确的，而且还应该坚定不移地推行下去。然而，在实施过程中过于单一，不加多元化的调 整, 显然不适合时代的需要。现在的现实环境导致学生大部分具有较强的功利性, 他们实际 
需要阅读古书的机会并不多, 认为学而无用, 不如不学。因此, 在坚持培养学生阅读古书能 力的同时, 还应加强与现代汉语等其他学科的联系, 把培养学生的古汉语知识在其他学科中 的运用能力作为教学目的。最起码让学生在纷杂的语言中有一点去伪存真的能力。

古今汉语是一脉相承的, 有源与流的关系, 现代汉语的文字、词汇、语法、语音、修辞 大部分等都是从古代汉语演变而来的, 要让学生认识到, 想学好现代汉语, 也要学好古代汉 语, 学习古汉语, 并不是脱离现实生活的学习, 是学以致用。把古代汉语的实用性作为教学 目的之一, 培养学生运用古汉语知识去深刻认识现代汉语, 去解决生活、学习中碰到的问题, 并从古代汉语中汲取营养, 增强现代汉语的表现力。教师在施教过程中, 关注汉语的古今联 系, 既要突出培养学生的古文阅读能力, 也要重点关注学生的古汉语知识在现代汉语中的运 用能力, 做好两手抓, 实现两手都很硬。

\section{2打破限制, 追求本真}

虽然在目前的教育评价体制当中, 我们的中小学生、本科生、甚至研究生还不得不沉溺 于各种各样的 “题海” 中, 将古代汉语等同于各种做题的技巧, 这样做恐怕是欠佳的。因为, 这样一来, 我们不仅不能进入传统文化的殿堂, 领会传统文化的精髓, 而且还会因此逐渐丧 失掉学生最宝贵的东西: 他们的激情、灵感、想象力和诸多生命的体悟。习题是枷锁, 但与 生命相关的这些东西却是自由的; 古代汉语作业终将会 “随风而逝” , 然而我们生命中的探 索激情和丰富想象是永恒的。

教育家马卡连柯说: “教师应该充满着对每一个他要与之打交道的具体的孩子的爱, 尽 管这个孩子的品质非常败坏, 尽管他可能会给教师带来很多不愉快的事情。”古代汉语的老 师, 在教学中首先要像阳光普照一样, 平等开放地爱每个学生, 教学内容首先要面向全体学 生。但是, 每一名学生在古代汉语学习中的认知、态度、能力等方面是有差异的。根据学生 的个性差异和具体情况, 有针对性地进行教学, 在传道授业解惑的同时, 使每个学生的才能 和特长得到充分的发挥, 实现古代汉语教学的最优化。尽量朝因材施教方向不断前行。

\section{2. 教师更新古代汉语的教学角度}

\section{1把握学科联系}

更新古代汉语的教学角度, 教学角度的选取是关键, 几十年古代汉语教材变化非常小, 开设古代汉语的课堂特别多, 很多老师就是按部就班的用一贯形成的方式讲授, 这样形成了 及其单一的死板的课堂, 墨守成规的教学方式, 老套的只注重文言文的一对一的古文翻译, 自己变成了不接受新鲜实物的书呆子, 又怎么能较好青春活力的孩子呢? 在这里我主张教师 在适当时候从古文字入手教学, 因为古文字很多都是出土资料中经过考证准确的没有太大争 论的字, 从甲骨文到金文到小管到隶书楷书这样一个演变过程, 几乎每一个字都承载着一段 历史, 文史不分家, 知道了历史, 在学习当时的文化, 学生从兴趣到喜欢, 最后再来看文选 的内容, 学生不知不觉进入到了一个新的境界。就如同建筑师建造大楼, 准备好了材料, 打 稳了地基, 那么大楼建成就指日可待了。举一例如下:

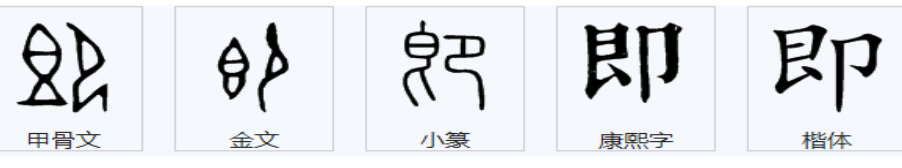

图1 “即” 的字体演变过程

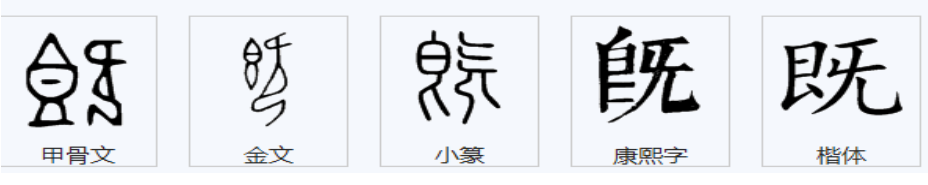

图2 “既” 的字体演变过程 
从字形上看即、既都是会意字，古文字写法是不同的。左边都是一个盛满食物的食器; 右边都是一个人, 但形态不同。“即” 的人面向食器,表示还没吃过; “既” 的人背向食器, 表示进食已经完毕。即、既的意义都和吃过有关。因为没有吃过, 所以 “即” 有未然义。它 可以表示靠近、接近，如 “可望而不可即” ; 空间的近再引申出时间的近，如 “高考在即”。 “即使” 为什么要用 “即” 呢? “即使” 只是一种假设, 事情还没有发生, 自当用表示未然的 “即”。因为已经吃过，所以“既”有已然义，“既成事实” “既往不各” “既得利益”， 包括 “既来之, 则安之”, 这里的 “既” 都有已经实现、已经完成的意思。“既然” 为什么 用 “既” 呢?因为 “既然” 说的是已经如此，当用表示已然的“既”。

如在讲古代汉语通论古今词义的异同时，可以举 “介”字，“介”古汉语的意思是 “一 名身穿铠甲的战士”，现代汉语成语 “一介武夫” 还保留着这个意思。在课堂教学和 “野外 作业” 时, 都可以将书本内容与方言联系起来, 拉近古代汉语学习与现代生活的距离, 缩短 学习古代汉语的时空感, 减轻怕学古代汉语的畏难情绪。安徽徽州方言保留了大量古代汉语 的要素, 特别是语音, 保留了古入声, 上课时即可举这样的例子。这种联系有其方便之处, 易收成效。人类的语言有相通之处, 可将古代汉语的学习与外语学习联系起来。如在讲古代 汉语文选翻译时, 老子的《道德经》第三十六章中有句 “将欲废之, 必固兴之; 将欲取之, 必固与之”, “将欲废之, 必固兴之”; 比如: 想要废弃某个团体, 不如让它兴盛, 等兴盛 到一定程度, 这个团体对社会的危害就会显露, 并且越来越大, 我们就可以趁机予以废除。 “将欲夺之, 必固与之”。比如: 有个小朋友的玩具比班里的其他人多, 我们想要夺取他的 玩具, 最好的办法, 就是把班里所有人的玩具都给这个小朋友。那么其他的小朋友没有玩具 可玩，他们就会愤怒的纷涌而上，把那个小朋友的玩具全部抢走。这就相当于英语中说的 "Those whom God wishes to destroy, he first makes mad."意思为: “上帝让你亡, 先让你疯狂”。 这种中英文对照学习法, 学生的印象相当深刻, 不仅拓展了知识面, 还调动了学生学习的乐 趣。

\section{2调动学生兴趣}

培养学生学习古代汉语不仅需要明确的目的, 还要有能够解决实际问题的能力; 如果无 的放矢, 为学习而学习, 那么学来的本领很多是一时的, 很容易遗忘。很多学生出于应试的 考虑, 根本不懂真正的由来和深刻的内涵, 只是死记硬背。更不用说了解其中蕴含的传统精 华, 这某种程度上也是现代很多人内心浮躁的原因之一。学好古代汉语这门课程, 能够帮助 学生顺利阅读古典文献, 继承和吸收古代文化精华。还能不断提升国民素质。比如当下中小 学生家长和老师之间存在的矛盾, 教师往往会对家长抱怨孩子的种种劣迹, 家长也会指责教 师的失职, 如果合理的运用所学古代汉语知识, 家长对老师说: “子不教, 父之过”。我想 再无奈的老师也会平息怒火说一声: “教不严, 师之惰”。教师与家长的地位是平等的, 教 师在与家长交往时, 需谦虚谨慎, 讲究礼貌, 营造和谐的气氛。这样才能缩短双方的距离, 家长才会敞开心扉。居高临下、盛气凌人的态度, 则往往会给家长留下粗俗的印象, 还可能 造成情绪上的对立。

我们要让学生明白: 我们将来当教师, 离不开古代汉语的素养; 做文书、秘书, 古代汉 语有很大的用处; 继承古代文化遗产, 建设新的文化, 更离不开古代汉语.....因此, 可在课 堂教学之外, 展开古代汉语教材教学探讨等活动, 让学生围绕某一个课题去搜集资料, 然后 汇总商讨, 既培养了学生的兴趣, 又扩充了知识; 可安排一定的时间带领学生参观博物馆等, 在参观中传授古代语言文字知识; 组织一些记忆力好的学生参加古典诗词研究会, 或身体力 行创作古典诗词等, 在实践中对古代汉语知识进行升华。

\section{3深入研究教材}

深入古代汉语的教学改革, 其中教材建设是重点。王力先生主编的《古代汉语》包括三 个部分, 即文选、通论、常用词。这三部分有机结合, 感性认识和理论知识融会贯通, 其合 
理性被学术界所公认，但是古代汉语教材 20 多年来内容变化不是很大，教材存在的问题主要 表现在: 一是理论知识没有汲取当前的研究成果, 使知识处于滞后状态; 二是注释太简单。 仅有释义, 没有相应的例句, 没有整句的串讲, 学生容易过目就忘, 留不印象下深刻。还有 当注不注的地方较多, 不便于学生自学; 三是解字、释义上也没有突出历代演变的概貌, 缺 乏古今联系。因此, 教学内容的革新还在于任课教师授课时的把握。古代汉语教师也应不断 学习研究深造, 积极掌握新资料, 不断佐证古代汉语的相关知识, 切不可抱有传统思想, 否 定新生力量, 那样古代汉语教学改革就会停滞不前。

在古代汉语教学中, 要把文选、通论、常用词三者纵横贯通联系起来。在文选教学中, 首先落实字词句, 让学生大体理解原文的同时, 加以相应的文献视频资料。在此基础上, 要 有意识地突出将要讲到的通论知识。例如, 在将要讲到通论古今词义的异同时, 先回顾讲文 选时, 着重突出的古今异议词, 甚至加入些中学时熟练掌握的古今异义词, 以便学生充分具 有这方面的感性认识, 然后在讲通论中的古今词义的异同时, 学生就可以将文选学习时获得 的感性认识自然而然地上升为理性认识。加深记忆, 温故知新。

通论知识通常是对文选讲解内容的归纳与升华。通论教学中，学生可用文选中的感性知 识来验证通论的理论; 通论教学后, 学生可用所学的理论知识去指导今后文选的学习实践。 教师也应在不断探索新知的过程中, 借助各种工具和现代教育技术, 寻找更多证据, 补充纠 正教材中出现的问题, 调动学生学习的热情。

\section{3. 教师研究古代汉语的教学方法}

很多人都说传统的古代汉语的教学方法比较刻板，我认为这种说法是欠佳的，至少是经 不住推敲的, 古代汉语不同于任何学科, 古代汉语是古代的文化知识, 没人生活在那个时代, 某种程度上不同于文学类学科存在着天马行空的成分, 它就是实实在在的, 不予许臆想的, 所以笔者以为, 讲授是古代汉语的主导, 其次是学生的补充。教学改革也是培养学生通过考 古发现的方式论证其中的知识, 而不是随意的使用别的学科的教学方式践踏古代汉语。

但是在新的时代背景下，在教学方法上应与时俱进改革的是以下三个小方面:

其一, 教学方法应以现代化手段为主。在数字时代, 运用现代化手段进行教学, 既能增 加知识的形象性, 符合当今学生的需要, 也能节省课堂时间, 事半功倍。教师可制作一些课 件, 可利用图片形式展示相关资料, 也可利用语音播放功能和视频播放功能把一些语音材料、 名篇朗读、经典场景提供给学生, 古代汉语的一些繁体字书写太费时, 用多媒体既方便又清 晰。

其二, 教学方法要有研究型和互动式为辅。研究型的主体是教师, 教师首先对其所用教 材深入研究, 借助各种工具和相关考古资料考释真伪, 并将古代汉语散落的碎片化知识点进 行整合。带动学生也深入研究。互动的前提是要学生了解当时的时代背景, 古汉语教学要想 生动活泼, 教师必须设计互动式内容, 采用启发式和讨论式教学, 让学生参与其中, 但是教 师是主导, 同时要避免或者说限制好学生的胡思乱说, 最后作好归纳、总结, 其教学效果比 灌输式教学要提高很多。

其三，教学方法要有实践性活动。实践性活动包括两个方面，一是练习训练。在古汉语 教学中, 我认为阅读方面的练习训练必须突出, 因为我们的教学目的是培养学生的古文阅读 能力, 而阅读能力的培养离不开实践性阅读。实践性活动的另一方面是让学生走出课堂, 把 学到的知识应用起来。如可以带学生到图书馆、博物馆去, 真实感受古籍的原貌; 可以带学 生到名胜古迹中去, 真实感受古代的氛围, 用学到的知识分析其中的语言现象。总之, 丰富 多彩的实践活动可以培养学生兴趣, 学以致用。 


\section{4. 教师合理利用 “国学热”}

在"国学热"的背景下, 结合古代汉语教学现状, 应以汉语的人文性特点为轴心深入改革 古代汉语教材, 以研究性学习方法为主导改革古代汉语教学模式, 以 “授人以鱼” 不如 “授 人以渔” 改革教学方法, 以重新认识古代汉语学习现实意义和社会价值为要旨开发与利用课 程资源, 激活古代汉语教学, 使该课程成为对学生的生活和终生发展有用的课程。

对待国学, 是实用主义的、功利化的态度, 还是以 “国学” 的文化、精神渗透进我们的 生命之中? 这的确是需要我们讨论和思考的。在中国人的心目中, 国学是 “修身、齐家、治 国、平天下” 这样一整套社会规范伦理、道德理念。历史, 是对已经发生的和正在发生的事 件进行记录整理和编织。国学, 作为传统, 是一种历史的创造和存在, 是一种我们必须践行 的文化方式, 是我们的祖先世世代代发明和积累起来的精神财富, 尽管我们有时与这种传统 文化存在着一种时间上的距离和心理上的距离, 但是, 它却是我们的历史和文化的基础, 构 成了我们精神生长的客观环境。所以, 从根本上来说, 我们正确的做法就是: 取其精华, 去 其糟粕。

能够研究国学, 首先要有深厚的古代文化知识作为基础, 并且通过各种方式获得正确的 解读途径, 不仅有利于自己的掌握, 更有利于文化的传播。所以某种程度上说国学课堂的精 彩是建立在精彩的古代汉语课堂基础之上。所以古代汉语老师应深化课堂改革, 转变思想观 念, 接受新知的同时深刻研究, 让古代汉语课堂伴随着国学热深入学生的生活。

\section{5. 结束语}

综上所述, 古代汉语教学改革的最大特点是针对古代汉语特殊的学科特点而言的, 一定 要打破一贯的跟风思想, 转变古代汉语 “填鸭式” 教学方法, 采用以讲授为主, 以研究、互 动、考查为辅相结合的方法可能会更好。合理利用当下 “国学热” , 教师学生深入研究古代 经典, 大力改革创新古代汉语课堂教学, 古代汉语课堂会迎来别样的天地。

\section{致谢}

感谢南京宇通实验学校郝美玲校长和赵健主任的有益探讨；感谢中央高校基本科研业务 费(2017B12914)的支持。

\section{References}

[1] M. H. Wang, Xingjuan Gao, Reflections on the reform of ancient chinese teaching, Journal of Shaoxing University, vol.26, pp. 53-55, 2006.

[2] Y. Qian, Analysis of the present situation of ancient chinese teaching and suggestions for reform, Journal of Inner Mongolia Normal University, vol.21, pp. 95-98, 2008.

[3] Z. Y. Chen, Discuss the teaching reformation of the ancient chinese language of higher pedagogical colleges, 2008 Annual Meeting of the Jiangxi Language Society, pp. 1-4, 2008.

[4] X. Z. Zhang, Craze for traditional chinese culture and reform of ancient chinese course, Literature and Art, vol.116, pp. 71-73, 2012.

[5] L. He, On the linking problems between ancient chinese course in normal universities and classical chinese teaching in middle schools, Education and Teaching Research, vol.29, pp. 81-84, 2015.

[6] Y. H. Zhong, Higher education, Hefei Univerisity of Technology Publishing House, 2009.

[7] Z. J. Shao, Education, East China Normal University Press, 2006. 
[8] D. S. Zhang, Probe and analysis of ancient chinese language teaching, Journal of Jiaozuo University, vol.24, pp. 112-114, 2010. 